http://www.jfas.info

\title{
DEVELOPMENT OF ANDROID APPLICATION FOR COMPUTATION OF AIR POLLUTANT INDEX AND WATER QUALITY INDEX
}

\author{
I. Z. Abidin ${ }^{1}$, F. S. Abdullah ${ }^{2}$, A. Azid ${ }^{1}$, M. K. A. Kamarudin ${ }^{1}$, M. A. Amran ${ }^{1}$ and H. Juahir ${ }^{1, *}$
}

${ }^{1}$ East Coast Environmental Research Institute (ESERI), Universiti Sultan Zainal Abidin, Gong Badak Campus, 21300 Kuala Nerus, Terengganu, Malaysia

${ }^{2}$ Faculty of Informatics and Computing, Universiti Sultan Zainal Abidin, Gong Badak Campus, 21300 Kuala Nerus, Terengganu, Malaysia

Published online: 08 August 2017

\begin{abstract}
Past few decades, human have experienced a revolution in the computer sciences, not only in terms of its ability but also in terms of its use. Advancement of smartphone technology had produced rapid yet incredible invention in many sectors such as construction, agriculture, education, health and many more. This paper will discuss about the development of the application that is used to calculate the API and WQI indices. WQI and API calculator application was named as My.Index Calculator. The application can run on Android version 3.0 (Honeycomb) until the latest version of it (Lollipop). The application provides better alternatives to the index calculation and data management. Now, the researchers and students can calculate the index value at anytime and anywhere with the help of the application. In addition, it is way easier and faster to calculate the index.
\end{abstract}

Keywords: water quality index; air pollutant index; programming; android.

Author Correspondence, e-mail: hafizanj@gmail.com

doi: http://dx.doi.org/10.4314/jfas.v9i2s.24 


\section{INTRODUCTION}

Environmental quality monitoring is an essential approach in order to create guidelines for a sustainable development. In Malaysia, both water and ambient air quality are monitored by the government agencies. An ambient air quality standard used to represent air quality status can assist public to determine whether the current air quality is dangerous or harmful to human health and also to the environment. Currently, Department of Environment (DOE) is monitoring the ambient air quality using 51 stations located nationwide. These stations are strategically placed in different area such as industrial, traffic and residential area as to detect any significant changes in the air pollutant concentration [1]. DOE had formulated an index system that is used to indicate the air quality status in simpler values instead using the actual concentration of every air pollutant DOE. Therefore, by knowing the air quality status, government and public can do intensive preparation so that mitigation measures in terms of medication supply and planning of outdoor activities can be taken. Malaysia uses Air Pollutant Index (API) as an indicator to represent the status of ambient air quality under the enforcement of DOE.

Similar as ambient air, water monitoring has its own quality index. A previous study has been made which use integrated measurement using a few water quality parameters to develop a single index [2]. These parameters are selected based on social, natural conditions and historical according to the different area and countries as to be used in the index calculation [3]. The water quality index is essential as it can be used to describe the actual water quality status using a single numeric score at a specific time at a particular location [4]. Hence, it is easier for information transfer from the local authorities to the public regarding the water quality status and its use. This effort will guide the public to use the water according to the water usage suitability. Despite the current environmental situation, precautions must be taken in order to protect public safety and health. Environmental monitoring must be conducted with the aim to observe the environmental quality status in human daily life. Monitoring phase included several steps before the data can be processed to represent the actual environmental condition. The first phase involves the field sampling to obtain the data regarding the concentration of pollutant. For air quality parameters, at least 24 hours are 
needed to obtain all the concentration of five selected pollutant. While for water quality, at least 5 days are needed to get the concentration value of all six water quality parameters as biochemical oxygen demand (BOD) requires 5 days reading to be used for index calculation. Then, after the data was obtained, a few steps of calculation are needed before getting the final index that represents the environmental status. Due to that, technologies regarding the environmental monitoring have been improved year after year. Nowadays, water quality parameters can be calculated in a single day. In addition, air quality pollutant can be measured instantaneously. The technicians are no longer needs to bring back the samples to the lab for sample analysis since the value can be obtained in-situ. Once all the parameter's values are obtained, only then the index can be calculated. However, the calculations for both water quality and air pollutant index are very tedious [5]. The calculations have several steps that need to be completed before getting a single index value. After all the efforts and time consumed during the field sampling and lab analysis, the calculation should be done with minimal effort and less time consuming. In conducting research, every minute and second must be taken into account so that it can be used as efficiently as possible. This can be achieved by applying computer science in the environmental field. In other words is by using computer programming to solve environmental problems.

Past few decades, human have experienced a revolution in the computer sciences, not only in terms of its ability but also in terms of its use. Together with the technological advancement, our country has undergone many changes and rapid development to compete with the outside world. Computer programming has been widely used and without realizing that it had been a crucial part of our daily life. Today, people heavily rely on computer, mobile phone, internet and other gadget to either connect to the other people or to solve daily life problems. Computer programming has been used to solve problem in many sectors such as education, engineering, health and environment. However, most of the tasks are performed using existing commercial software packages. Somehow, not all existing software packages can solve specific problem arose during conducting research. Due to that, a simple application or software can be developed if there is no suitable software available in the market.

This is considered important to learn computer programming since anyone can create 
applications in order to solve other different problems. It is also crucial for non-computer science student to learn computer programming since they will have a better understanding about their background knowledge. Hence, they able to create better applications that fulfil the requirements and conditions to solve the problem along with providing the answer. The research goal is to design a mobile application to help users to calculate and store WQI and API data. This paper will discuss about the development of the application that is used to calculate the API and WQI indices.

\section{SMARTPHONE DEVELOPMENT}

Advancement of smartphone technology had produced rapid yet incredible invention in many sectors such as construction, agriculture, education, health and many more. Nowadays, a smartphone can be considered as a small version of computer due to its capabilities where it not only make telephone calls and text messages, but also have many additional sophisticated features. The features may include send and receive e-mail, impressive quality of the camera, GPS receiver, accelerometer, internet access and easy touch screen operation [6-7]. Latest smartphones are equipped with internal storage ranging from 8 gigabytes up to 128 gigabytes. Due to the large storage capacity, the smartphones can be used to store a huge amount of data or files at a time. Apart from that, with the processors and memories that are as good as personal computer makes it convenient enough to run any software and can cover wider usage. One of the advantages of smartphones' capability is to construct a data management scheme that is used to organize temporal or spatial data [7]. The usage of the smartphone also can be utilized in the environmental field to help students or other personnel to conduct their research.

One of the major mobile device's operating system, Android was developed and owned by Google. This operating system runs on various types of mobile devices made by different resources across the world. Since the usage of Android mobile phones is up to millions and keep increasing, thus making the wider usage of any application can be achieved. Development of Android application required specific tools provided by Google such as Android Software Developer's Kit (Android SDK) which can be obtained from Android 
Developers website (http://developer.android.com). Android Studio is the official integrated development environment (IDE) in developing an application. All the designation and programming in this paper are using

Android Studio version 1.2.3 and the programming language used is Java. Apart from that, software such as Android Development Tools (ADT) also required for the development process. The application is built using an extensible mark-up language (XML) and tested using virtual machine which imitates an Android phone. All the software and plug-ins are free to download. Until today, there are loads of free online tutorial and books available that can be used as a revision for development of an Android application [7].

\section{RESULTS AND DISCUSSION}

The application can run on Android version 3.0 (Honeycomb) until the latest version of it (Lollipop). WQI and API calculator application was named as My.Index Calculator. Fig. 1 shows the front page of the application and has four option buttons to be selected by the users. Each button represents different activity that leads to different activity layout. "Water Quality Index" and "Air Pollutant Index" buttons lead to the layouts that have brief information about the indices. The information includes all the parameters measured for the index calculation as can be seen in Fig. 2. This allows people with no environmental science knowledge to have a general view of what environmental pollution is all about without referring to any other notes. Apart from that, the actual formulas for the index calculation were also included in the application. This allows users to know what formula used and how the index calculation was done inside the application. The users can use the formula as reference in case manual calculation is intended. The formula layout is shown in Fig. 3. The main feature of the application is the calculator to calculate WQI and API. There are two tabs for each of the layouts which are the calculator tab and saved data tab. In the calculator tab, there are several empty spaces with hints used to guide the users on where to insert the parameter's value. The application was pre-set to only perform calculation when all the spaces are filled with a sampling location and values. Otherwise, if the user is missing to fill up one space, the calculation will not take place. Then, the application also will not carry out the calculation if 
the sampling location is found similar with the sampling location that already saved in the saved data. The calculator layout can be seen in Fig. 4.

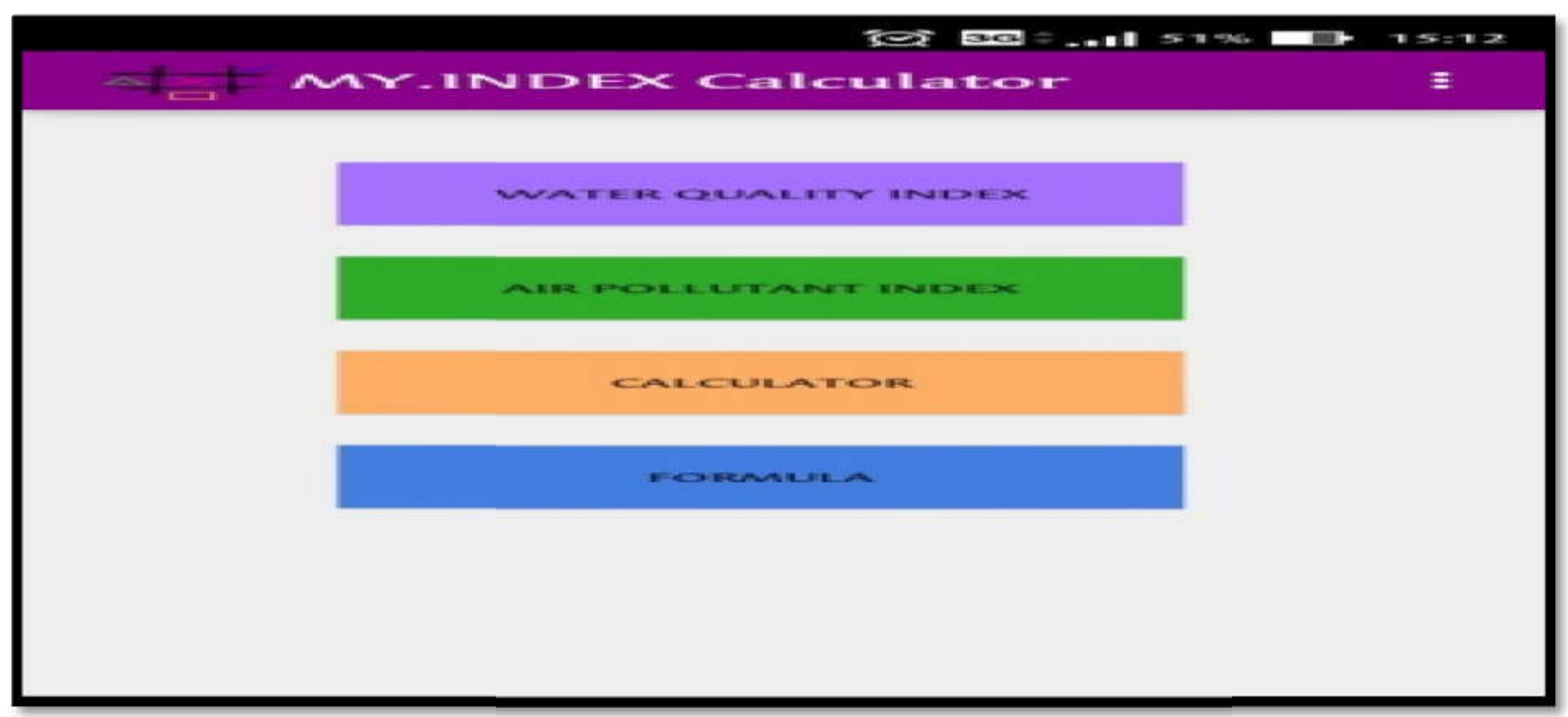

Fig.1. My.Index calculator front page

\begin{tabular}{|c|c|}
\hline 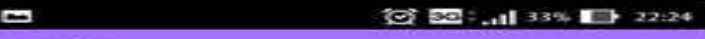 & 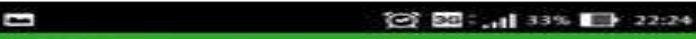 \\
\hline I I Water Quality inctex & I I Air Pollutant Index \\
\hline $\begin{array}{l}\text { 1) Dissolved oxygen, DO } \\
\text { DO concentration is affected by } \\
\text { temperature, pressure, salinity and } \\
\text { organism activity in a water body. } \\
\text { DO concentration can drop below } \\
\text { essential level due to the pollution } \\
\text { caused either by anthropogenic } \\
\text { activities or natural factors. Plant } \\
\text { and aquatic organisms are highly } \\
\text { dependent on the DO } \\
\text { concentration. }\end{array}$ & $\begin{array}{l}\text { 2) Nitrogen dioxide }\left(\mathrm{NO}_{2}\right) \\
\mathrm{NO} \text { is considerably more toxic than } \\
\mathrm{NO} \text { and most of the issues related to } \\
\text { the health problem have been } \\
\text { related with } \mathrm{NO}_{2} \text {. NO, can alter } \\
\text { lumg function and increase } \\
\text { susceptibility to respiratory } \\
\text { inspections. NO, also contributes to } \\
\text { acid rain as it cam be comverted into } \\
\text { nitric acid in the atmosphere. }\end{array}$ \\
\hline $\begin{array}{l}\text { 2) Biochemical oxygen demand: } \\
\text { BOD is an amount of oxygen needed } \\
\text { to oxidize the organic matter in a } \\
\text { water body. Natural organic matter } \\
\text { consists of plant and leaf fall. Urban } \\
\text { runoff carries high amounts of } \\
\text { pollutamts such as pesticide, } \\
\text { fertilizer, and other nutrients can } \\
\text { increase the BOD concentration. } \\
\text { Oxygen used in the decomposition } \\
\text { process robs the other oxygen that }\end{array}$ & $\begin{array}{l}\text { 3) Carbon monoxide (CO) } \\
\text { Carbon momoxide is a gas and is } \\
\text { found in air. The main sources of } \\
\text { carbon monoxide are volcanoes. } \\
\text { smoking, motor vehicle exhaust and } \\
\text { some industrial activities, such as } \\
\text { making steel. Increased levels of } \\
\text { carbon monoxide reduce the } \\
\text { amount of oxygen carried by } \\
\text { hemogiobin around the body in red } \\
\text { blood cells. The result is that vital } \\
\text { organs, such as the brain, nervous }\end{array}$ \\
\hline
\end{tabular}

Fig.2. WQI and API formula 

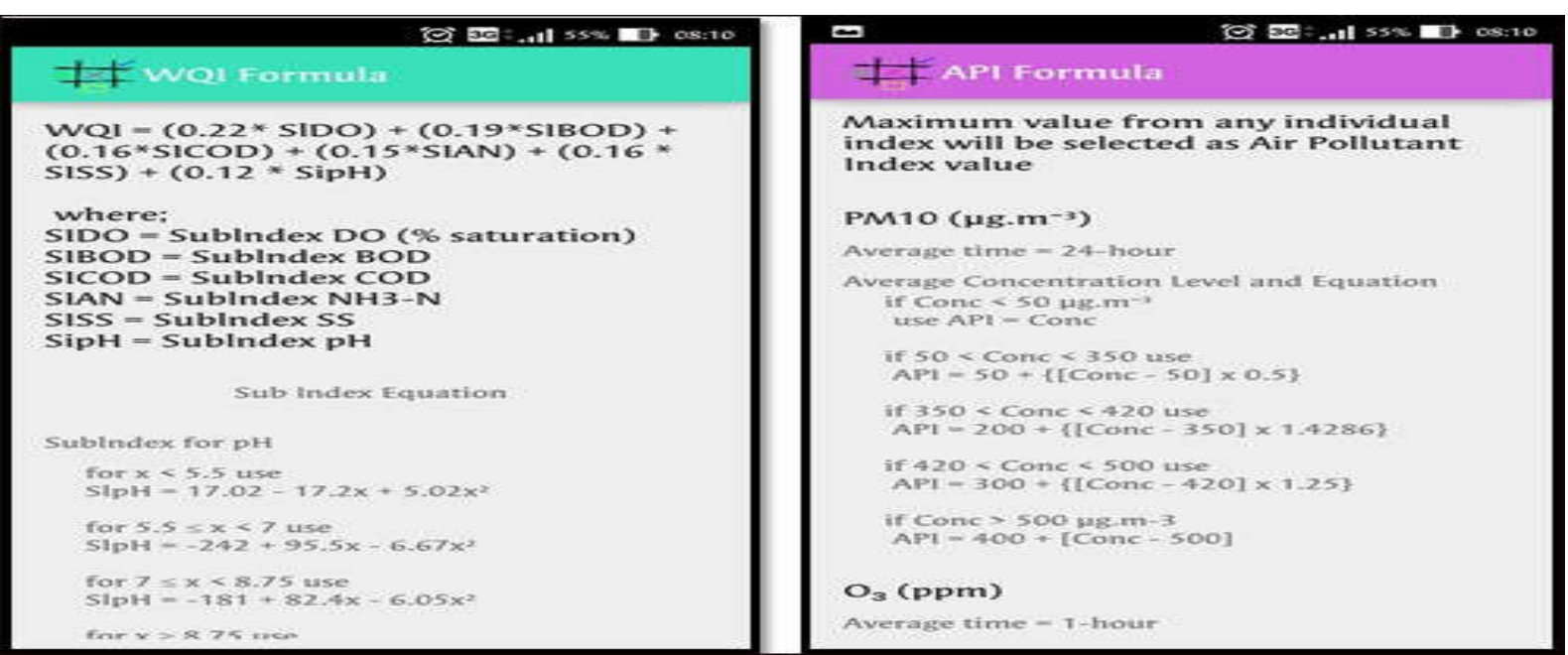

Fig.3. WQI and API formula

Another important feature of the application is the ability to store data in the database. The Android was integrated with the SQLite database to store the text file inside the device memory. All the inserted values comprise parameters and sub-index values are stored in the database as can be seen in Fig. 5. This allows the users to store and keep the data for future reference without having to write it back into a piece of paper. Since the database is totally dependent with the device memory, it is able to store huge amount of data. The SQLite also allow the users to delete the saved data once it's no longer needed. Users worldwide can download the application through Google Play Store.

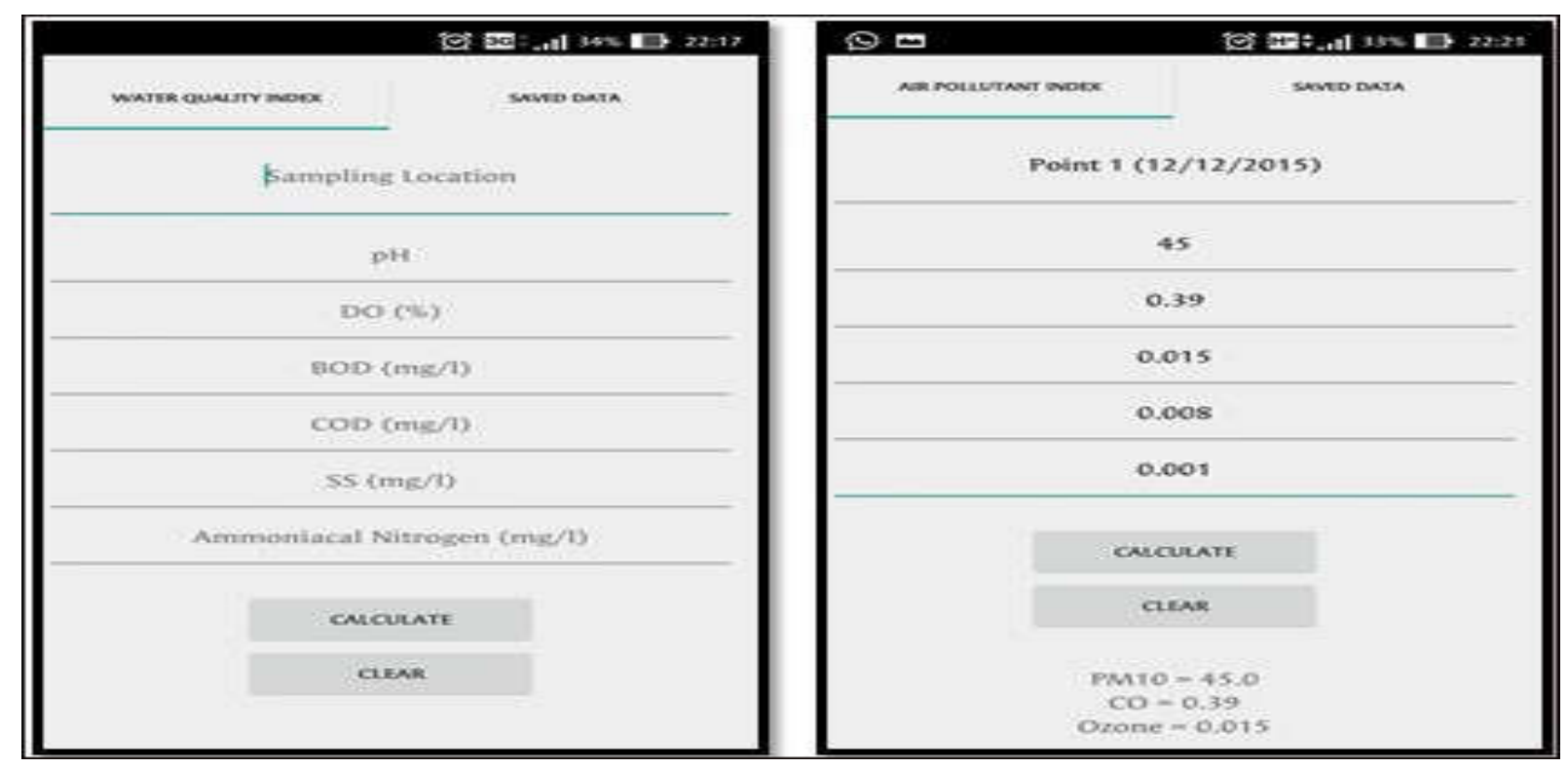

Fig.4. My.Index calculator's user interface 


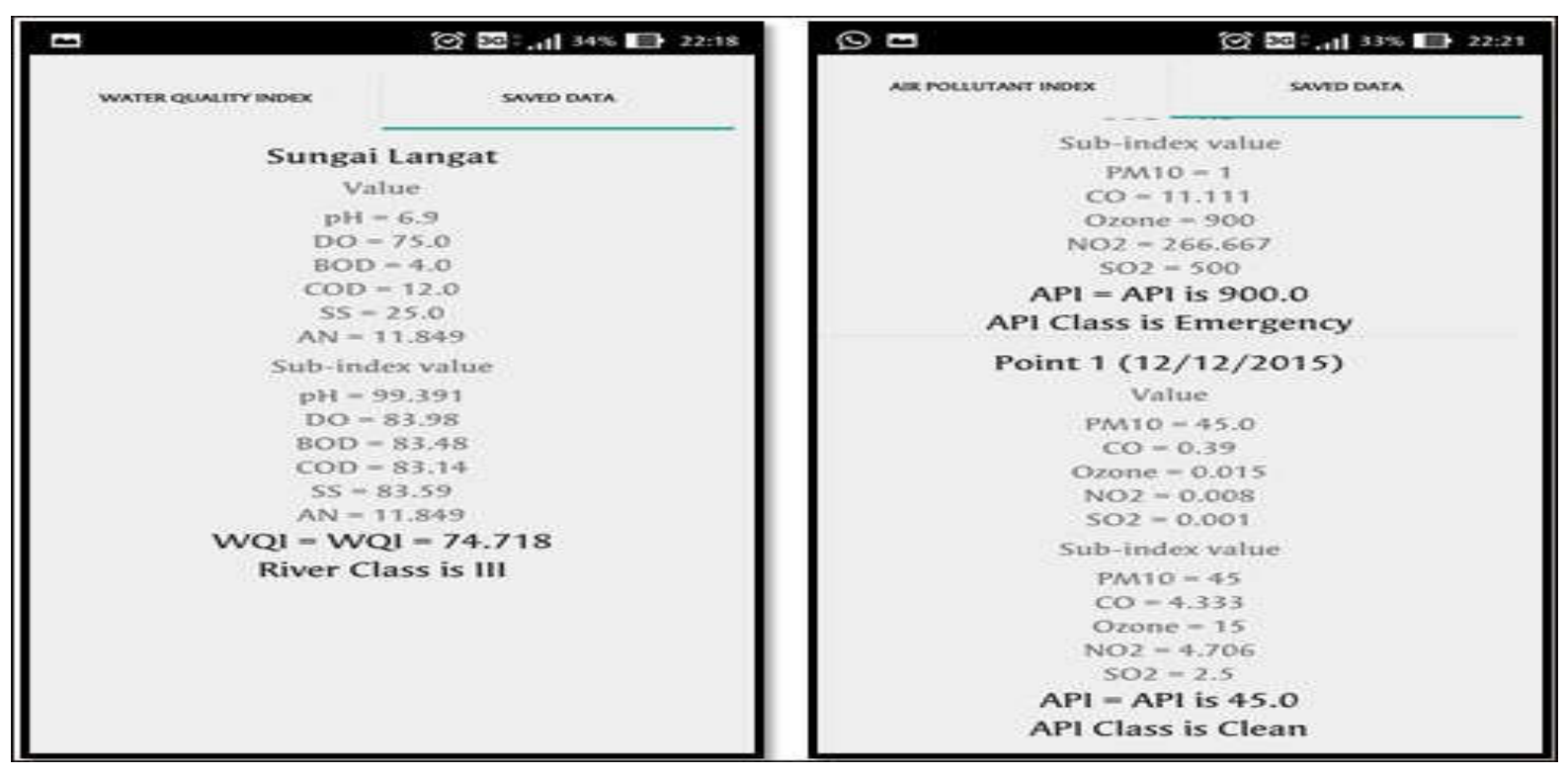

Fig.5. Data stored in SQL database

\section{EXPERIMENTAL}

\subsection{Application Development Framework}

Development framework is a guideline that is used to plan, structure and control the process of developing an application. However, in computer systems, a framework is consisting of several layered structures representing how the application can be built and how the structure would inter-relate [8]. Fig. 6 shows the framework used for the development of the application. 


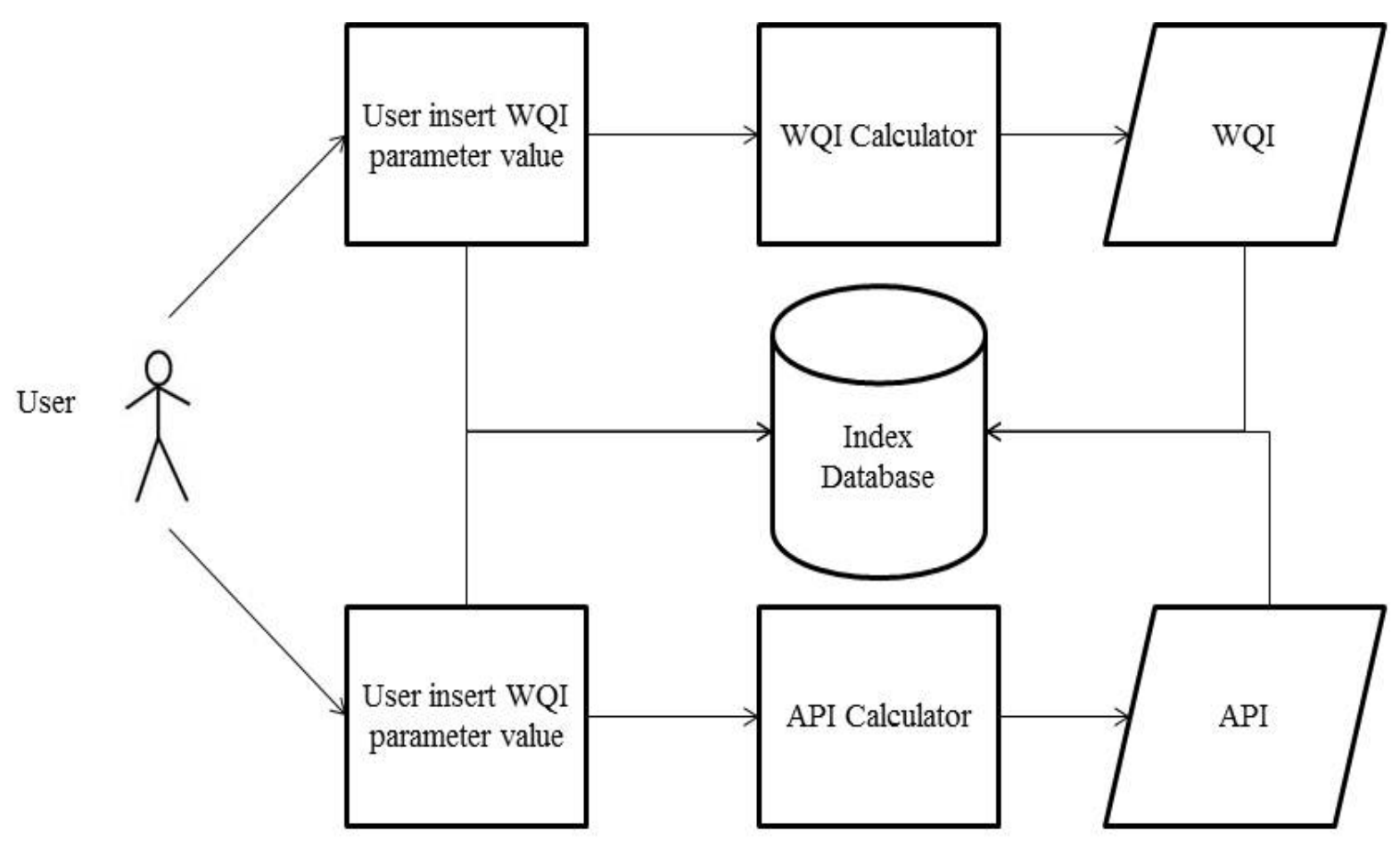

Fig.6. Android application development framework 
Table 1. Equation for the estimation of sub-index values

\begin{tabular}{|c|c|c|}
\hline Parameter & Sub-Index Formula & Range \\
\hline \multirow{3}{*}{ DO (in \% saturation) } & $\mathrm{SI}_{-\mathrm{DO}}=0$ & for $\mathrm{x} \leq 8$ \\
\hline & SI-DO $=100$ & for $x \geq 92$ \\
\hline & SI-DO $=-0.395+0.030 * x^{2}-0.00020 * x^{3}$ & for $8<x<92$ \\
\hline \multirow{2}{*}{ BOD } & $\mathrm{SI}_{-\mathrm{BOD}}=100.4-4.23 * \mathrm{x}$ & for $\mathrm{x} \leq 5$ \\
\hline & $\mathrm{SI}_{-\mathrm{BOD}}=108 * \mathrm{e}^{-0.055 \mathrm{x}}-0.1 * \mathrm{x}$ & for $x>5$ \\
\hline \multirow{2}{*}{ COD } & SI- ${ }_{\mathrm{COD}}=-1.33 \mathrm{x}+99.1$ & for $\mathrm{x} \leq 20$ \\
\hline & $\mathrm{SI}_{\mathrm{COD}}=103 * \mathrm{e}^{-0.0157^{*} \mathrm{x}}-0.04 * \mathrm{x}$ & for $x>20$ \\
\hline \multirow{3}{*}{$\mathrm{NH}_{3}-\mathrm{N}$} & $\mathrm{SI}_{\mathrm{AN}}=100.5-105 \mathrm{x}$ & for $\mathrm{x} \leq 0.3$ \\
\hline & SI- ${ }_{\text {AN }}=94 * e^{-0.573 x}-5 * I x-2 I$ & for $0.3<\mathrm{x}<4$ \\
\hline & $\mathrm{SI}_{-\mathrm{AN}}=0$ & for $x \geq 4$ \\
\hline \multirow{3}{*}{ SS } & SI-sS $=97.5 * \mathrm{e}^{-0.00676 \mathrm{x}}+0.05 * \mathrm{x}$ & for $x \leq 100$ \\
\hline & SI-sS $=71 * \mathrm{e}^{-0.0016 \mathrm{x}}-0.015 * \mathrm{x}$ & for $100<\mathrm{x}<1000$ \\
\hline & $\mathrm{SI}_{-\mathrm{SS}}=0$ & for $x \geq 1000$ \\
\hline \multirow{4}{*}{$\mathrm{pH}$} & $\mathrm{S} l_{-\mathrm{pH}}=17.02-17.2 * \mathrm{x}+5.02 * \mathrm{x}^{2}$ & for $\mathrm{x}<5.5$ \\
\hline & $\mathrm{S} 1_{-\mathrm{pH}}=-242+95.5 * \mathrm{x}-6.67 * \mathrm{x}^{2}$ & for $5.5 \leq x<7$ \\
\hline & $\mathrm{S} 1_{\mathrm{pH}}=-181+82.4 * \mathrm{x}-6.05 * \mathrm{x}^{2}$ & for $7 \leq \mathrm{x}<8.75$ \\
\hline & $\mathrm{S} 1_{-\mathrm{pH}}=536-77.0 * \mathrm{x}+2.76 * \mathrm{x}^{2}$ & for $x \geq 8.75$ \\
\hline
\end{tabular}

Note: *means multiply with $\mathrm{X}$ is the concentration of the indicated parameter in $\mathrm{mg} / \mathrm{L}$ except for $\mathrm{pH}$ and $\mathrm{DO}$

\subsection{WQI and API Formula}

Initially, the application requires the user to insert WQI or API parameter value in the application. The parameters for WQI and API can be seen in Table 1 and Table 2 accordingly. Both of the tables show the equation needed in order to calculate the sub-index of WQI and API. WQI can be determined using the formula [1]. Meanwhile, for API, a higher sub-index value from all the sub-indices are selected as the main index as shown in Table 3.

$\mathrm{WQI}=(0.22 * \mathrm{SIDO})+(0.19 * \mathrm{SIBOD})+(0.16 * \mathrm{SICOD})+(0.15 * \mathrm{SIAN})+(0.16 * \mathrm{SISS})+(0.12 * \mathrm{SipH})$ where SIDO is Sublndex DO (\% saturation), SIBOD is Sublndex BOD (mg/l), SICOD is 
Sublndex COD (mg/l), SIAN is Sublndex NH3-N (mg/l), SISS is Sublndex SS (mg/l), SipH is Sublndex pH. Symbol * means multiply with.

Table 2. Formula for estimation of air pollutant sub-index [12]

\begin{tabular}{|c|c|c|c|}
\hline Pollutant & $\begin{array}{c}\text { Average } \\
\text { Time } \\
\end{array}$ & $\begin{array}{c}\text { Average } \\
\text { Concentration Level } \\
\end{array}$ & Equation \\
\hline \multirow[t]{5}{*}{$\mathrm{PM}_{10}$} & 24-hour & Conc $<50 \mu \mathrm{g} . \mathrm{m}^{-3}$ & $\mathrm{API}=\mathrm{Conc}$ \\
\hline & & $50<$ Conc $<350$ & $\mathrm{API}=50+\{[$ Conc -50$] \times 0.5\}$ \\
\hline & & $350<$ Conc $<420$ & $\mathrm{API}=200+\{[$ Conc -350$] \times 1.4286\}$ \\
\hline & & $420<$ Conc $<500$ & $\mathrm{API}=300+\{[$ Conc -420$] \times 1.25\}$ \\
\hline & & Conc $>500 \mu \mathrm{g} \cdot \mathrm{m}^{-3}$ & $\mathrm{API}=400+[$ Conc -500$]$ \\
\hline \multirow[t]{4}{*}{$\mathrm{CO}$} & 8-hour & Conc $<9$ ppm & $\mathrm{API}=$ Conc $\mathrm{x} 11.11111$ \\
\hline & & $9<$ Conc $<15$ & $\mathrm{API}=100+\{[$ Conc -9$] \times 16.66667\}$ \\
\hline & & $15<$ Conc $<30$ & $\mathrm{API}=200+\{[$ Conc -15$] \times 6.66667\}$ \\
\hline & & Conc $>30 \mathrm{ppm}$ & $\mathrm{API}=300+\{[$ Conc -30$] \times 10\}$ \\
\hline \multirow[t]{3}{*}{$\mathrm{O}_{3}$} & 1-hour & Conc $<0.2 \mathrm{ppm}$ & $\mathrm{API}=\mathrm{Conc} \times 1000$ \\
\hline & & $0.2<$ Conc $<0.4$ & $\mathrm{API}=200+\{[$ Conc -0.2$] \times 500\}$ \\
\hline & & Conc $>0.4 \mathrm{ppm}$ & $\mathrm{API}=300+\{[$ Conc -0.4$] \times 1000\}$ \\
\hline \multirow[t]{4}{*}{$\mathrm{NO}_{2}$} & 1-hour & Conc $<0.17 \mathrm{ppm}$ & API = Conc $\times 588.23529$ \\
\hline & & $0.17<$ Conc $<0.6$ & $\mathrm{API}=100+\{[$ Conc -0.17$] \times 232.56\}$ \\
\hline & & $0.6<$ Conc $<1.2$ & $\mathrm{API}=200+\{[$ Conc -0.6$] \times 166.667\}$ \\
\hline & & Conc $>1.2 \mathrm{ppm}$ & $\mathrm{API}=300+\{[$ Conc -1.2$] \times 250\}$ \\
\hline \multirow[t]{4}{*}{$\mathrm{SO}_{2}$} & 24-hour & Conc $<0.04 \mathrm{ppm}$ & $\mathrm{API}=$ Conc $\mathrm{x} 2500$ \\
\hline & & $0.04<$ Conc $<0.3$ & $\mathrm{API}=100+\{[$ Conc -0.04$] \times 384.61\}$ \\
\hline & & $0.3<$ Conc $<0.6$ & $\mathrm{API}=200+\{[$ Conc -0.3$] \times 333.333\}$ \\
\hline & & Conc $>0.6 \mathrm{ppm}$ & $\mathrm{API}=300+\{[$ Conc -0.6$] \times 500\}$ \\
\hline
\end{tabular}




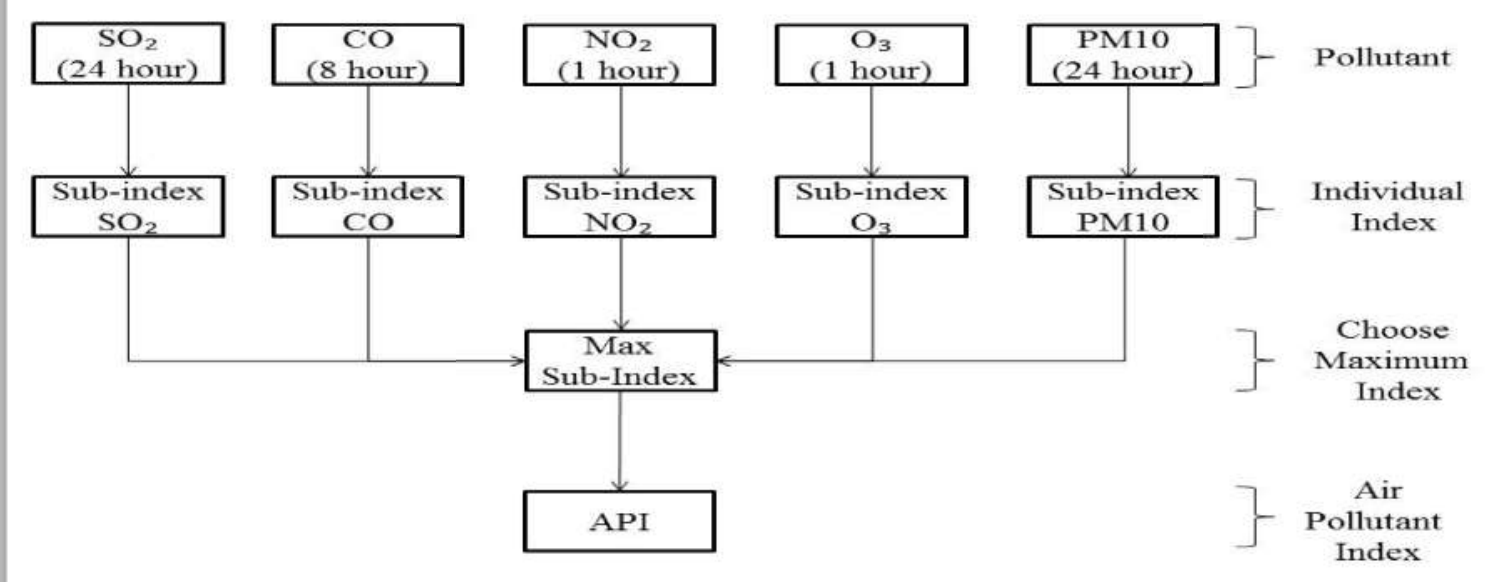

Fig.7. Calculation of air pollutant index [12]

\subsection{WQI and API Calculator Mechanism}

All the calculation and other related information are used in the application development. The development is done using Android Studio, the official integrated development (IDE) for Android platform development developed by Google. The psuedocode is first converted to Java programming language and inserted accordingly into Java class in Android Studio. All the calculations are inserted in this process along with the assignation of indices' classes and statuses straight from the calculated value

\subsection{SQLite Data Dictionary}

SQLite is an open source SQL database that capable to stores data on a smartphone or device. SQLite database is a lightweight database that comes with the Android operating system [9]. In SQL, the data dictionary is a set of database tables that used to store information about the database definition. The dictionary consists of information about the database objects, for example tables, indexes, columns, data types and description. The data dictionary used in SQL database is automatically updated whenever objects are changed, removed, added or edited within the database [10]. SQLite database structures for the application can be represented as Table 3 and Table 4 accordingly. All of these data will be stored inside the SQLite database once the calculation is completed. 
Table 3. Data dictionary for API database

\begin{tabular}{|c|c|c|}
\hline Field Name & Type & Description \\
\hline ID & Integer & Unique ID value for every input \\
\hline Sampling location & Text & $\begin{array}{l}\text { Location name or sample number to } \\
\text { differentiate every input }\end{array}$ \\
\hline Input PM10 & Integer & Input value of PM10 \\
\hline Input $\mathrm{CO}$ & Integer & Input value of $\mathrm{CO}$ \\
\hline Input $\mathrm{O}_{3}$ & Integer & Input value of $\mathrm{O}_{3}$ \\
\hline Input $\mathrm{NO}_{2}$ & Integer & Input value of $\mathrm{NO}_{2}$ \\
\hline Input $\mathrm{SO}_{2}$ & Integer & Input value of $\mathrm{SO}_{2}$ \\
\hline Sub-index PM10 & Integer & Calculated value of sub-index PM10 \\
\hline Sub-index CO & Integer & Calculated value of sub-index $\mathrm{CO}$ \\
\hline Sub-index $\mathrm{O}_{3}$ & Integer & Calculated value of sub-index $\mathrm{O}_{3}$ \\
\hline Sub-index $\mathrm{NO}_{2}$ & Integer & Calculated value of sub-index $\mathrm{NO}_{2}$ \\
\hline Sub-index $\mathrm{SO}_{2}$ & Integer & Calculated value of sub-index $\mathrm{SO}_{2}$ \\
\hline API value & Integer & Calculated value of API \\
\hline API class & Text & Class of API depends on the API value \\
\hline
\end{tabular}

Table 4. Data dictionary for API database

\begin{tabular}{ccc}
\hline Field Name & Type & Description \\
\hline ID & Integer & Unique ID value for every input \\
Sampling location & Text & Location name or sample number to differentiate every input \\
Input $\mathrm{pH}$ & Integer & Input value of $\mathrm{pH}$ \\
Input DO & Integer & Input value of DO \\
Input BOD & Integer & Input value of BOD \\
Input COD & Integer & Input value of COD \\
Input SS & Integer & Input value of SS \\
\hline
\end{tabular}




\begin{tabular}{|c|c|c|}
\hline Input AN & Integer & Input value of AN \\
\hline Sub-index $\mathrm{pH}$ & Integer & Calculated value of sub-index $\mathrm{pH}$ \\
\hline Sub-index DO & Integer & Calculated value of sub-index DO \\
\hline Sub-index BOD & Integer & Calculated value of sub-index BOD \\
\hline Sub-index COD & Integer & Calculated value of sub-index COD \\
\hline Sub-index SS & Integer & Calculated value of sub-index SS \\
\hline Sub-index AN & Integer & Calculated value of sub-index AN \\
\hline WQI value & Integer & Calculated value of WQI \\
\hline WQI class & Text & Class of WQI depends on the WQI value \\
\hline
\end{tabular}

\section{CONCLUSION}

The users from nationwide are expected to use the application since the application is free to download without any charges applied. The application provides better alternatives to the index calculation and data management. Now, the researchers and students can calculate the index value at anytime and anywhere with the help of the application. In addition, it is way easier and faster to calculate the index, thus, making time management more efficient. The database function in the application can help to provide better data management. Users can easily refer to the stored data for future references. Despite all the function and usage, the main goal is to learn computer science and use it to provide better alternatives in solving environmental problems. It is a good approach to see how to solve the environmental problems using different perspectives such as computer programming. In addition, by having a different perspective can help people to understand the scenarios or problem in a better way. Meaning that, thinking based on multiple-perspective can create better chances of generating solutions thus increases problem solving performance. Apart from that, the application can be used as a teaching tool for a high school student and public to get basic knowledge on water and air pollutant index [11].

\section{ACKNOWLEDGEMENTS}

We thank the Director of East Coast Environmental Research Institute (ESERI) of University 
of Sultan Zainal Abidin to provide facilities during conducting this study.

\section{REFERENCES}

[1] Department of Environment (DOE). Air quality-Continuous air quality monitoring (CAQM). Putrajaya: Ministry of Natural Resources and Environment, 2010

[2] Department of Environment (DOE). A guide to air pollutant index in Malaysia. Putrajaya: Ministry of Natural Resources and Environment, 1997

[3] Zandbergen P A, Hall K J. Analysis of the British Columbia water quality index for watershed managers: A case study of two small watersheds. Water Quality Research Journal of Canada, 1998, 33(4):519-549

[4] Tsuzuki Y. Relationships between pollutant discharge and water quality in the rivers from "better" to "worse" water quality. Ecological Indicators, 2015, 52:256-269

[5] Kaurish F W, Younos T. Developing a standardized water quality index for evaluating surface water quality. Journal of the American Water Resources Association, 2007, 43(2):533-545

[6] Gazzaz N M, Yusoff M K, Aris A Z, Juahir H, Ramli M F. Artificial neural network modeling of the water quality index for Kinta River (Malaysia) using water quality variables as predictors. Marine Pollution Bulletin, 2012, 64(11):2409-2420

[7] Lantzos T, Koykoyris G, Salampasis M. FarmManager: An Android application for the management of small farms. Procedia Technology, 2013, 8:587-592

[8] Weng Y H, Sun F S, Grigsby J D. GeoTools: An android phone application in geology. Computers and Geosciences, 2012, 44:24-30

[9] Rouse M. Definition-framework. 2015, http://whatis.techtarget.com/definition/framework [10] Tamada R. Android SQLite database tutorial. 2011, http://www.androidhive.info/2011/11/android-sqlite-database-tutorial/

[11] Wenzel K. What is a data dictionary? 2015, http://www.essentialsql.com/what-is-a-data-dictionary 
[12] Abidin I Z, Juahir H, Azid A, Mustafa A D, Azaman F. Application of excel-VBA for computation of water quality index and air pollutant index. Malaysian Journal of Analytical Sciences, 2015, 19:1056-1064

\section{How to cite this article:}

Abidin IZ, Abdullah FS, Azid A, Kamarudin MKA, Amran MA, Juahir H.Development of android application for computation of air pollutant index and water quality index. J. Fundam. Appl. Sci., 2017, 9(2S), 352-367. 